\title{
Effects of the Composition and Crystal Structure of Zinc-Nickel Alloy Deposits on the Internal Strain
}

\author{
Yutaka TSURU* and Masako TAN KKA
}

\author{
Received June 7, 1995 ; Accepted October 11, 1995
}

\begin{abstract}
An average internal strain in the electrodeposited $\mathrm{Zn}-\mathrm{Ni}$ alloy films was in situ measured using the resistance wire type strain gauge setup on the reverse side of the copper substrate. The solid-state stripping voltammetry and periodic reverse current electrolysis were also applied for the investigation of the effects concerning the partial electroleaching of $\mathrm{Zn}$ from the deposits on the processing mechanism of the internal strain. The deposits were composed of the dominant $\gamma$-phase containing an excess of $\mathrm{Zn}$ and the internal strain was always in compression. However, the internal strain sharply changed from compressive to tensile when a part of $\mathrm{Zn}$ was selectively electroleached from the deposits under periodic reverse plating. The formation of compressive strain in the $\mathrm{Zn}-\mathrm{Ni}$ alloy deposits was obviously not dependent on the crystal structure but related to the excessive amounts of $\mathrm{Zn}$ contained in the dominant $\gamma$-phase.
\end{abstract}

\section{INTRODUCTION}

An electroplated $\mathrm{Zn}-\mathrm{Ni}$ alloy exists in the form of three dominant phases; $\eta, \gamma$ and $\alpha^{\prime \prime}$. The $\eta$-phase is a solid solution of $\mathrm{Ni}$ in $\mathrm{Zn}$ with a $\mathrm{Ni}$ solubility of less than 1 at \%". A part of the $\mathrm{Zn}$ in these alloys tends to be chemically or electrochemically etched out ${ }^{33}$.

The Ni content of the $\mathrm{Zn}-\mathrm{Ni}$ alloy coatings utilized for the steel frame of automob les and for the plastic coated steel sheets is around 15 at $\%$ and the dominant structure is the $\gamma$-phase ${ }^{4}$. Such $\mathrm{Zn}-\mathrm{Ni}$ alloy coatings are favorable for the protection of steel against corrosion ${ }^{5.6)}$. The internal stress in these deposits is always compressive during electroplating. However, upon turning off the current, the internal stress sharply changes from compressive to tensile. The tensile stress seems to simultaneously result in many cracks on the surface of the deposits ${ }^{71}$.

In the present research, a resistance wire type strain gauge meter was used for successive measurement of the internal strain in the deposits during electroplating ${ }^{8}$ and solid-state stripping veltammetry was applied for the anodic dissolution of the deposits ${ }^{0.10)}$. We also discussed the effects concerning the partial electroleaching of $\mathrm{Zn}$ from the deposits on the internal strain in the

Kyushu Institute of Technology, Faculty of Engineering (1-1. Sensuicho. Tobata-ku, Kitakyushu Cify, Fukuoki. Japan, 804)

Key Words: Electrodeposition, Zinc-Nickel Alloy, Crystal Structure, Internal Strain deposits under periodic reverse (PR) plating.

\section{EXPERIMENTAL}

The plating baths with their compositions listed in Table I were used without stirring at $50^{\circ} \mathrm{C}$. Electroplating was performed using a potentio/galvano-static method and potentiostatic PR method. Table 2 shows the potentiostatic PR plating conditions. Each deposition was followed by in situ analysis of the alloy deposits by linear potential scan stripping voltammetry at a rate of $10 \mathrm{mV} / \mathrm{s}$ without removing the electrode from the solution. All potentials were measured and reported on the basis of a $\mathrm{Ag} / \mathrm{AgCl}$ sat. $\mathrm{KCl}$ reference electrode. The distance between the test electrode and the top of Luggin capillary was kept at $1.5 \mathrm{~mm}$ in length. The test electrode was separated from the counter electrode by a plastic

Table 1 Composition of the test plating baths.

\begin{tabular}{|l|l|c|c|}
\hline & Alloy bath & Ni bath & Zn bath \\
\hline $\mathrm{NiSO}_{4} 6 \mathrm{H}_{2} \mathrm{O}$ & $1.00 \mathrm{M}$ & $1.00 \mathrm{M}$ & - \\
$\mathrm{ZnSO}_{4} 7 \mathrm{H}_{2} \mathrm{O}$ & $0.50 \mathrm{M}$ & - & $0.50 \mathrm{M}$ \\
$\mathrm{H}_{3} \mathrm{BO}_{3}$ & $0.32 \mathrm{M}$ & $0.32 \mathrm{M}$ & $0.32 \mathrm{M}$ \\
$\mathrm{NH}_{4} \mathrm{Cl}$ & $0.26 \mathrm{M}$ & $0.26 \mathrm{M}$ & $0.26 \mathrm{M}$ \\
$\mathrm{Na}_{2} \mathrm{SO}_{4}$ & - & $0.67 \mathrm{M}$ & $1.33 \mathrm{M}$ \\
\hline $\mathrm{pH}$ & & 4.0 \\
\hline
\end{tabular}

M; mol dm 
Table 2 Potentiostatic PR plating conditions.

\begin{tabular}{|c|c|c|c|c|c|c|}
\hline Condition & $\mathrm{A}$ & $\mathrm{B}$ & $\mathrm{C}$ & $\mathrm{D}$ & $\mathrm{E}$ & $\mathrm{F}$ \\
\hline $\mathrm{Tc}(\mathrm{s})$ & (DC) & 5.0 & 5.0 & 5.0 & 5.0 & 5.0 \\
$\mathrm{Ta}(\mathrm{s})$ & & 0.01 & 0.1 & 1.0 & 2.0 & 5.0 \\
$\theta(\mathrm{s})$ & & 5.01 & 5.1 & 6.0 & 7.0 & 10.0 \\
\hline
\end{tabular}

Tc; Duration per cycle for cathodic deposition at $\mathrm{E}=-1.025 \mathrm{~V}$.

$\mathrm{Ta}$; Duration per cycle for anodic dissolution at $\mathrm{E}=-0.82 \mathrm{~V}$.

$\theta$; Pulse period.

panel in order to maintain an uniform current distribution. The substrate metal for the electroplating was the $0.6 \mathrm{~mm}$ thick commercial copper plate. The copper plate was cut into a rectangular size of $25 \mathrm{~mm}$ long by $8 \mathrm{~mm}$ wide and annealed in a vacuum at $350^{\circ} \mathrm{C}$ for 2 hours.

The average internal strain in the deposits was successively detected using a resistance wire type strain gauge setup on the reverse side of the copper substrate having a preferred crystal orientation of (200) plane. The copper electrode was immersed and lied perpendicular with its exposed surface in the plating bath after electropolishing in $50 \mathrm{v} / \mathrm{v} \%$ phosphoric acid ${ }^{\mathrm{y}}$. The strain gauge was expected to precisely reflect the average residual stress in the deposits since it expanded and contracted with the bending of the copper substrate during electroplating ${ }^{\text {th }}$.

The composition of the deposits was evaluated using an atomic absorption analyzer while the crystal structure was determined using X-ray diffractometry (XRD). The morphology was examined using a scanning electron microscope (SEM).

\section{RESULTS AND DISCUSSION}

\section{1 An average internal strain in the deposits}

An internal strain in deposits can depend to a large extent on the composition of plating solutions. Figure 1 shows the relation between the integrated quantity of passed electricity $(\mathrm{Qc})$ and the internal strain in the deposits obtained at cathodic current density of $3.0 \mathrm{~A}$ $\mathrm{dm}^{-2}$. The internal strain of the $\mathrm{Ni}$ film deposited from the Ni bath was significantly tensile. The internal strain of the $\mathrm{Zn}$ film deposited from the $\mathrm{Zn}$ bath was slightly compressive. On the other hand. the internal strain of the $\mathrm{Zn}-\mathrm{Ni}$ alloy film deposited from the alloy bath was significantly compressive and it changed from compressive to tensile with the time of exposure after the current was turned off.
The Ni content in the alloy film obtained at a cathodic current density of $3.0 \mathrm{Adm}^{-2}$ was 11.7 at $\%$ and the crystal structure was mostly the $\gamma$-phase on the basis of the XRD pattern shown in Fig. 2. Upon closer examination using the XRD method by Kondo ${ }^{12}$, the $\mathrm{Zn}-\mathrm{Ni}$ alloy deposits of a $\mathrm{N} /$ content of less than 11.6 at $\%$ existed as the mixture consisted of the $\gamma$-phase and the $\mathrm{Zn}$-rich $\eta$-phase. The refore, it gave an indication that such a deposit of $11.7 \mathrm{at} \% \mathrm{Ni}$ in Fig. 2 presumably consisted of the $\gamma$-phase containing excessive amounts of $\mathrm{Zn}$ since the $\mathrm{Ni}$ content of pure $\gamma$-phase was in the region of 15 to 26 at $\% ?$.

\subsection{The variation of the current density and internal strain with the linear potential scanning}

Figure 3 shows the relation between the potentialinternal strain in the ceposit and the potential-current density per cycle obtained by the liner potential sweep method in the alloy bath ${ }^{13}$. In the diagram the electrode potential was classificd into three different regions in order to represent the variation of current density in further detail. An integrated quantity of electricity passed during the cathodic reduction was $5.14 \mathrm{Ccm}^{2}$

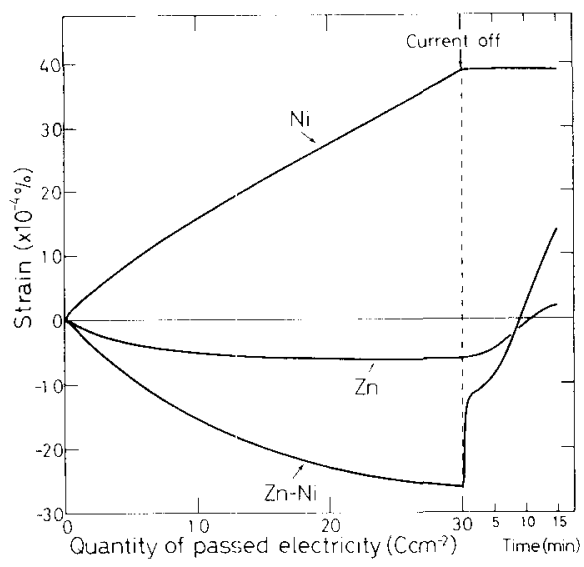

Fig. 1 Time variation in the average internal strain in the deposits obtained at cathodic current density of $3.0 \mathrm{Adm}{ }^{2}$ from various plating baths listed in Table 1.

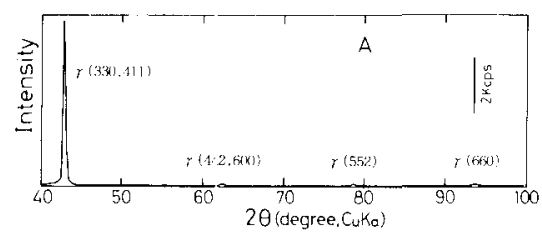

Fig. $2 \mathrm{X}$-ray diffraction patterns of the deposit obtained at the potentiostatic condition of $\mathrm{E}=-1.025 \mathrm{~V}$ from the alloy bath. 


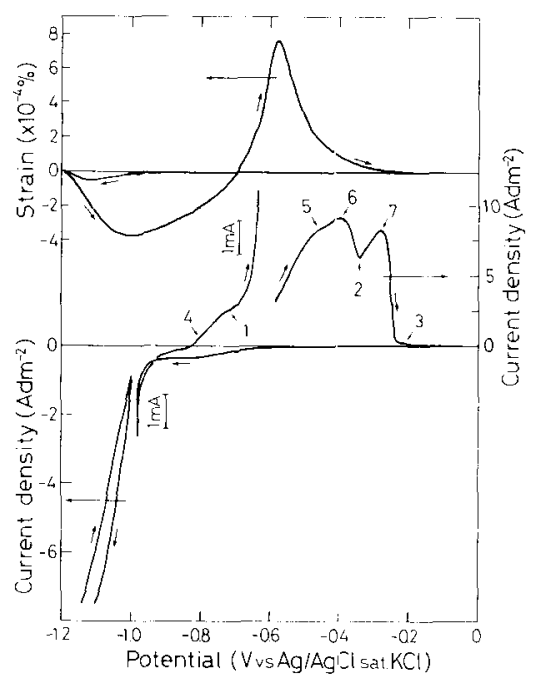

Fig. 3 Variation in the current density and average internal strain in the deposits obtained with linear potential scanning at a rate of $10 \mathrm{mVs}^{-1}$ in the alloy bath.

and the integrated stripping charges of an alloy deposit were 0.03, 3.75 and $5.02 \mathrm{Ccm}^{-2}$ at each point for 1,2 and 3 as shown in Fig. 3, respectively. A similar stripping peak structure has recently been reported by Karwas (4).

The linear potential scan stripping analysis of the alloy deposits revealed current peaks corresponding to the existence of the $\mathrm{Zn}$-rich $\gamma$-phase and to the dissolution of the remaining porous $\mathrm{Ni}$ at a more noble anode potential. The stripping current 4 corresponded to the preferential electrodissolution of $\mathrm{Zn}$ from the $\mathrm{Zn}$-rich $\gamma$-phase in the alloy deposits. As a product of this process, an $\alpha$-phase or porous Ni phase might be formed. The stripping peaks 5 and 6 were due to the electroleaching of $\mathrm{Zn}$ from the $\gamma+\alpha$-phases ${ }^{14}$. This process also produced a porous $\mathrm{Ni}$ matrix and then it was stripped off giving rise to current peak 7 occurred at a more noble potential. Therefore, the electroplated $\mathrm{Zn}-\mathrm{Ni}$ alloys seem to be the deposits composed of the dominant $\gamma$ phase containing the excessive amounts of $\mathrm{Zn}$.

The internal strain in the alloy deposits was compressive at the beginning of electrodeposition as observed in Fig. 3. The compressive strain increased with an increase in cathodic overpotential that reached a maximum value at the electrode potential of $\mathrm{E}=-1.10 \mathrm{~V}$ and near the cathodic current density of $7.0 \mathrm{~A} \mathrm{dm}^{2}$, However, above a current density of more than 7.0A $\mathrm{dm}^{-2}$, the compressive strain decreased step by step with the increase in current density. On the other hand, the limiting current density $\left(i_{L}\right)$ of the zinc cations in the alloy bath was approximately $6.9 \mathrm{Adm}^{-213}$. Therefore, the diffusion of the zinc cations to the electrode surface became the rate determing step provided that the current density increased by more than 7.0 $\mathrm{Adm}^{-2}$, which resulted in the deposits composed of relatively $\mathrm{Ni}$-rich crystals compared with that of the underlying one ${ }^{15}$. The tension of the upper deposited Ni-rich coating offset the compression in the previously formed underlying deposits. Thus, it was possible to interpolate from the viewpoint of film composition why the compressive strain in the deposit decreased with an increase in cathodic overpotential after reaching the maximum compression close to the potential of $\mathrm{E}=-1.10 \mathrm{~V}$.

After the electrode potential was inverted at $\mathrm{E}=$ $-1.20 \mathrm{~V}$ as shown in Fig. 3, the compressive strain increasing again with a decrease in the cathodic current density and reached a maximum value at the potential of $\mathrm{E}=-1.01 \mathrm{~V}$. However, the direction of the internal strain gradually changed from compressive to tensile during the selective electroleaching of a part of the excess $\mathrm{Zn}$ in the alloy deposit. The compressive strain decreased to apparent zero value at an anodic integrated charge of $0.04 \mathrm{C} \mathrm{cm}^{-2}$. At the potential of $\mathrm{E}=-0.68 \mathrm{~V}$ a part of the $\mathrm{Zn}$ began to selectively electroleach from both the $\gamma$-phase and the porous $\gamma$-phase. At a potential more noble than $E=-0.68 \mathrm{~V}$, the tensile strain in the alloy deposits sharply reached a maximum value during the anodic dissolution of the deposits. Eventually, the porous $\mathrm{Ni}$ matrix was also anodically stripped off. However, the internal strain was inclined to return to its initial value at the beginning of plating while the remaining $\mathrm{Zn}-\mathrm{Ni}$ alloy deposits were consumed step by step during the electrodissolution with anodic polarization.

3. 3 The internal strain in the deposits under potentiostatic PR plating

The anodic current appeared at a potential close to $\mathrm{E}=-0.83 \mathrm{~V}$ in Fig. 3. It corresponded to the beginning of electroleaching of $\mathrm{Zn}$ from the $\mathrm{Ni}-\mathrm{Zn}$ alloy deposit. Therefore, $\mathrm{E}=-1.025 \mathrm{~V}$ was selected as cathode potential for the alloy deposition and $E=-0.82 \mathrm{~V}$ as anode potential for the selective dissolution of $\mathrm{Zn}$ from the alloy deposit under the potentiostatic PR plating.

Figure 4 shows the relation between the internal 


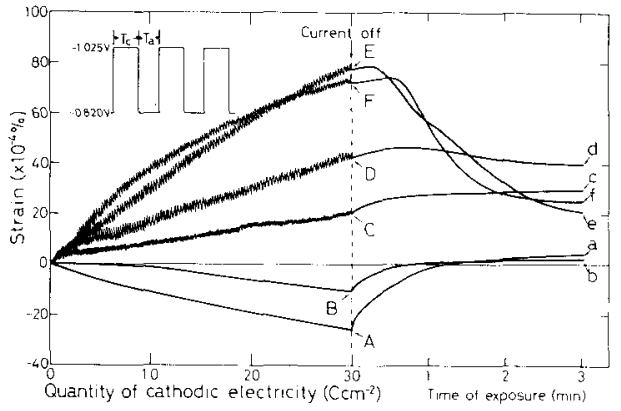

Fig. 4 Influence of the PR plating conditions listed in Table 2 on the average internal strain in the deposits obtained from the alloy bath.

strain in the deposits and the integrated quantity of electricity (Qc) passed for cathodic deposition at $\mathrm{E}=$ $-1.025 \mathrm{~V}$. The duration per cycle for the $\mathrm{Zn}-\mathrm{Ni}$ alloy deposition was always kept at $\mathrm{Tc}=5.0 \mathrm{~s}$, where the quantity of passed cathodic electricity (qc) per cycle was $19 \pm 1 \mathrm{Cdm}^{-2}$, while the duration per cycle for anodic dissolution of $\mathrm{Zn}$ from the alloy deposits was varied in the range of $\mathrm{Ta}=0$ to $5.0 \mathrm{~s}$ under the PR plating conditions (A to F) listed in Table 2. During potentiostatic deposition at $\mathrm{E}=-1.025 \mathrm{~V}$, the internal strain was always compressive. But, the internal strain continuously changed from compressive to tensile with an increase in Ta from 0 to $2.0 \mathrm{~s}$ and every deposit was crack-free immediately after the PR plating as shown in Fig. 5 (A, E). However, at $\mathrm{Ta}=5.0 \mathrm{~s}$ the internal strain-time curve was almost identical to one at $\mathrm{Ta}=2.0 \mathrm{~s}$ and the deposit had always many cracks even immediately after the deposition as shown in Fig. $5(\mathrm{~F})$.

After the current was turned off, the tensile strain in the films deposited at $\mathrm{Ta}=2.0$ and $5.0 \mathrm{~s}$ stagnated for a few minutes and then it greatly decreased with an increase in immersion time in the test solution. The many cracks consequently appeared in the deposit obtained at $\mathrm{Ta}=2.0 \mathrm{~s}$ even after three minutes immersion as shown in Fig. 5(e). It could, therefore, be presumed that the initiation and growth of cracks resulted in releasing the internal tensile strain in the deposit at $\mathrm{Ta}$ $=5.0 \mathrm{~s}$.

The internal strain of the deposits oscillated cyclically with time during PR plating. Figure 6 shows a part of the exaggerated relation between the internal strain-time curve and the current-time curve obtained at the condition of $\mathrm{Tc}=\mathrm{Ta}=5.0 \mathrm{~s}$. Although the average internal strain in deposit was tensile, the instantaneous
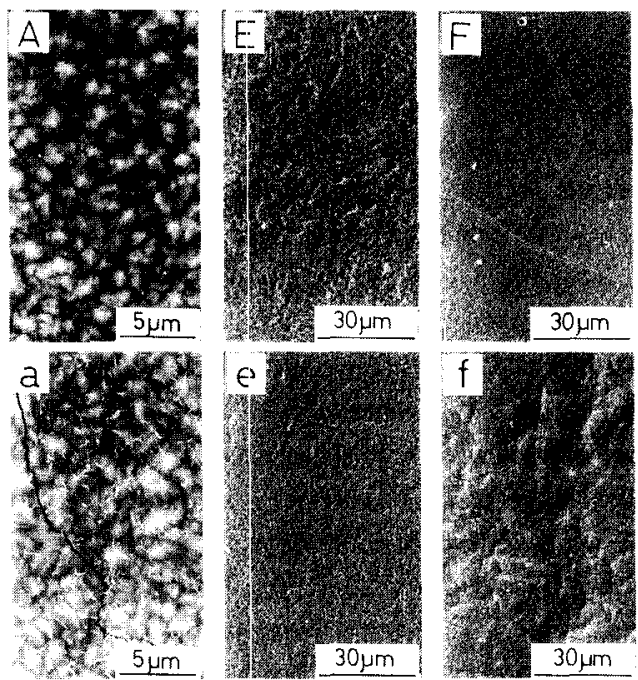

Fig. 5 Influence of the PR plating conditions on the surface morphology of the deposits obtained from the alloy bath Symbols are the same as for Fig. 4. (A) (E) (F); immediately after electroplating. (a) (e) (f): after 3 min immersion in the test solution.

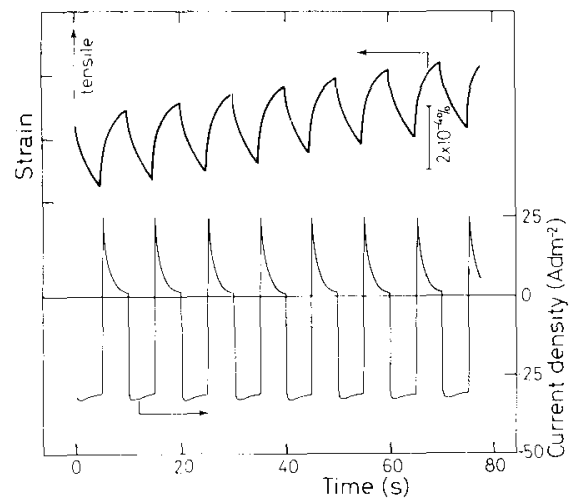

Fig. 6 Time variation in the current density and average internal strain in the deposits obtained at the PR plating condition of $\mathrm{F}$ in Table 2 from the alloy bath

strain changed cyclically from compressive during the deposition to tensile during the anodic dissolution of the deposit for every cycle as shown in Fig. 6 . In other words, the internal strain in as-deposited $\mathrm{Zn}-\mathrm{Ni}$ alloy films was always compressive and the instantaneous strain sharply changed from compressive to tensile as soon as a little of $\mathrm{Zn}$ was selectively electroleached from the alloy deposits.

The internal strain in the deposit passed through the 
zero value with increasing of Ta in Fig. 4. Figure 7 shows the influence of Ta on the internal strain of the deposits at $\mathrm{Qc}=30 \mathrm{Ccm}^{-2}$ and quantity of passed electricity (qa) per cycle for anodic dissolution of the deposits under the PR plating condition of $\mathrm{Ec}=-1.025 \mathrm{~V}$. Ea $=-0.82 \mathrm{~V}$ and $T c=5.0 \mathrm{~s}$. The solid symbol corresponds to the deposit having many cracks. The internal strain and qa increased with an increase of Ta together. In the Ta region of longer than $1.0 \mathrm{~s}$, the qa eventually reached the steady value of $3.7 \mathrm{Cdm}^{-2}$. On the other hand, the internal strain sharply increased at near $\mathrm{Ta}=$ $1.0 \mathrm{~s}$ and then at $\mathrm{Ta}=5.0 \mathrm{~s}$ it decreased to similar value as one obtained at $\mathrm{Ta}=2.0 \mathrm{~s}$ depending upon the cracks formed on its surface. Therefore, it was obvious that the internal strain resulted in apparent zero value under the PR plating condition of $\mathrm{Ta}=0.024 \mathrm{~s}$ and $\mathrm{qa}=0.28 \mathrm{C}$ $\mathrm{dm}^{2}$ at $\mathrm{Tc}=5.0 \mathrm{~s}$ in Fig. 7. The ratio of the qa to qc, of which value was $19 \pm 1 \mathrm{C} \mathrm{dm}{ }^{2}$, was equal to about 1.5 $\times 10^{-2}$.

\section{4 Crystal structure of the alloy deposits}

Figure 8 shows the $\mathrm{X}$-ray diffraction patterns of the Zn-Ni alloy films deposited under PR plating conditions listed in Table 2, where the alloy plating duration was $\mathrm{Tc}=5.0 \mathrm{~s}$ and the anodic duration was varied in the range of $\mathrm{Ta}=0$ to $5.0 \mathrm{~s}$ for every cycle.

During the anodic duration of $\mathrm{Ta}=0$ to $1.0 \mathrm{~s}$, the preferred crystal orientation of the deposits continuously changed from the $\gamma-(330,411)$ plane to the $\gamma(442,600)$ plane with an increase in Ta. At the same time, the tensile strain in the crack-free deposits also monotonously increased with Ta. On the other hand, the

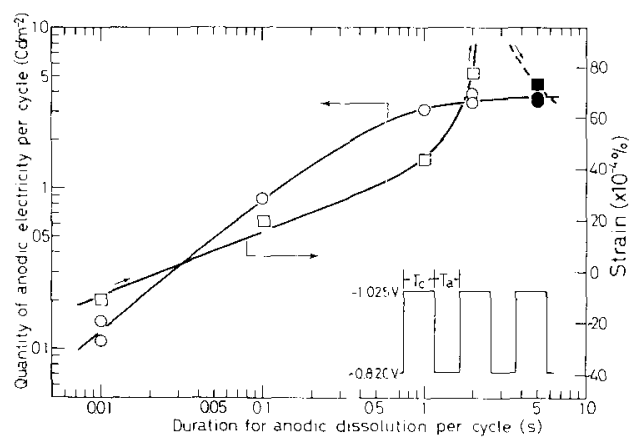

Fig. 7 Influence of the duration per cycle for anodic dissolution under the PR plating conditions listed in Table 2 on the quantity of anodic electricity per cycle and average internal strain in the deposits obtained at the total quantity of cathodic electricity of $30 \mathrm{C} \mathrm{cm}^{-2}$ from the alloy bath preferred crystal orientation of the films deposited at $\mathrm{Ta}=2.0$ and 5.0 s was the $\gamma(330,411)$ plane again and the alloy film deposited at $\mathrm{Ta}=5.0$ s showed a great tensile strain with many cracks cven immediately after the deposition.

Table 3 shows the current efficiency and chemical compositions of the films deposited under the various plating conditions. With an increase of Ta, the current efficiency decreased and the Zn content also decreased from 88.3 at $\%$ in the films deposited potentiostatically at $\mathrm{E}=-1.025 \mathrm{~V}$ to 85.6 at $\%$ obtained under the PR plating condition of $T \mathrm{c}=\mathrm{Ta}=5.0 \mathrm{~s}$. But their crystal structures had almost the same preferred crystal orientation of the $\gamma(330,411)$ plane in spite of the different $\mathrm{Zn}$ contents and opposite internal strain. From these results, it was obvious that the formation of compressive strain in the

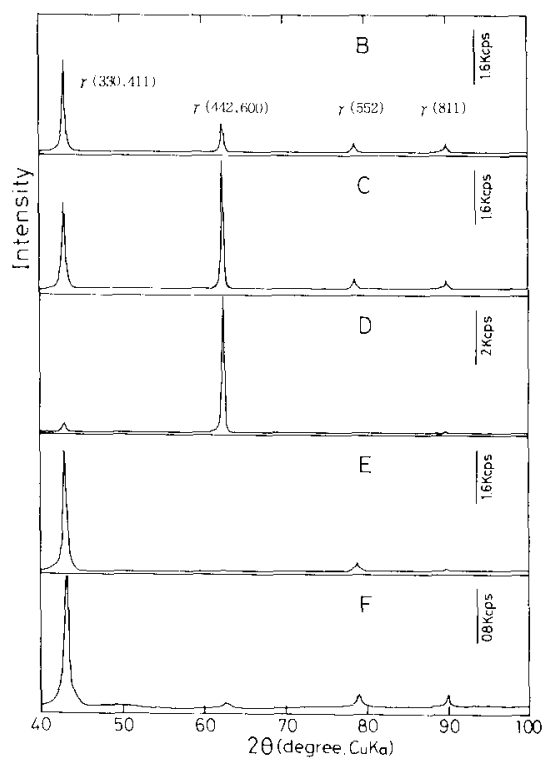

Fig. 8 Influence of the PR plating conditions on the $X$-ray diffraction patterns of deposits obtained from the alloy bath. Symbols are the same as for Fig. 4.

Table 3 Variations of the current efficiency and $\mathrm{Zn}$ content in alloy deposits under the $P R$ plating conditions listed in Table 2.

\begin{tabular}{|l|c|c|c|c|c|c|}
\hline Condition & A & B & C & D & E & F \\
\hline CE $(\%)$ & 99.0 & 99.0 & 98.0 & 88.0 & 84.0 & 83.0 \\
\hline C (Zn)(at\%) & 88.3 & 87.8 & 87.5 & 87.1 & 85.8 & 85.6 \\
\hline
\end{tabular}

$\mathrm{CE}$ : Current efficiency, $\mathrm{C}(\mathrm{Zn}) ; \mathrm{Zn}$ content in alloy deposit 
$\mathrm{Zn}-\mathrm{Ni}$ alloy deposits was not dependent on the crystal structure but related to the excessive amounts of $\mathrm{Zn}$ contained in the dominant $\gamma$-phase.

\section{CONCLUSIONS}

A resistance wire type strain gauge setup on the reverse side of the copper substrate successively detected the time-variation of an average internal strain in the $\mathrm{Zn}-\mathrm{Ni}$ alloy deposit. The internal strain in the deposits, which was composed of the dominant $\gamma$-phase containing an excess of $\mathrm{Zn}$, was always in compression. The internal strain sharply changed from compressive to tensile when a part of $\mathrm{Zn}$ was selectively electroleached from the deposits. Under the potentiostatic PR plating conditions, the instantaneous strain fluctuated cyclically from compressive during $\mathrm{Zn}-\mathrm{Ni}$ alloy deposition to tensile during its anodic dissolution. The formation of compressive strain in the $\mathrm{Zn}-\mathrm{Ni}$ alloy deposits was obviously not dependent on the crystal structure but related to the excessive amounts of $\mathrm{Zn}$ contained in the dominant $\gamma$-phase.

\section{Reference}

1) E. Raub and K. Muller, Fundamentals of Metal Deposition, p. 144. Elsevier (1967).
2) M. Hansen and K. Anderko, Constitution of Binary Alloys, p. 1059, McGraw-Hill (1958)

3) D. W. Siitari, M. Sagiyama and T. Hara, Trans, Iron Steel Inst. Japan, 23, 959 (1983).

4) A. Shibuya, T. Kurimoto, K. Korekawa and K. Noji, TETSU-TO-HAGANE, 66, 77I (1980).

5) R. Noumi, H. Nagasaki, Y. Foboh and A. Shibuya, SAE Technical Papers Series 820332 (1982).

6) J. W. Dini and H. R. Johnson, Metal Finishing, 77, 31, 53 (Aug. 1979).

7) K. Ikeda and H. Satoh, TETSU-TO-HAGANE, 77. 1162 (1991).

8) Y. Tsuru, Y. Nakanura, R. Takaue and K. Hosokawa, Denki Kagaku, 60,780 (1992).

9) S. Swathirajan, J. Electrochem. Soc.. 133, 671 (1986).

10) M. F. Mathias and T.W. Chapman. J. Electrochem. Sor.. 134, 1408 ( 1987).

11) G. Fisher, Galvanotechnik, 53, 335 (1962)

12) Y. Ohomori, K. Kondo, K. Kamei and S. Hinotani. Mater. Res. Soc. Symp. Prcc., 122, 553 (1988).

13) Y. Tsuru, M. Tanaka and K. Hosokawa, Denki Kagaku, 63, 117 (1995).

14) C. Karwas and T. Hopel, J. Electiochem. Sor., 135.839 (1988)

15) T. Akiyama and H. Fukushima, Trans, Iron Steel Inst. Japan, 32, 787 (1992). 